\title{
GAMBARAN PERILAKU DAN PENGATURAN PENGGUNAAN TELEPON GENGGAM CERDAS (TGC) PADA SISWA SEKOLAH MENENGAH KEJURUAN
}

\author{
Jap Tji Beng ${ }^{1,5}$, Hartinah Dinata ${ }^{2,5}$, Vivien H. Wangi ${ }^{3,5}$, Sri Tiatri ${ }^{4,5, *}$ \\ ${ }^{1}$ Fakultas Teknologi Informatika, Universitas Tarumanagara, Jakarta \\ Email:t.jap@untar.ac.id \\ ${ }^{2}$ Fakultas Psikologi, Universitas Tarumanagara, Jakarta \\ Email: hartinah.717182023@stu.untar.ac.id \\ ${ }^{3}$ Fakultas Psikologi, Universitas Tarumanagara, Jakarta \\ Email: vivien.825160007@stu.untar.ac.id \\ ${ }^{4}$ Fakultas Psikologi, Universitas Tarumanagara, Jakarta \\ *) Corresponding Author Email: sri.tiatri@untar.ac.id \\ ${ }^{5}$ Science, Technology, and Society Research Group, Universitas Tarumanagara, Jakarta
}

Masuk : 27-12-2020, revisi: 29-09-2021, diterima untuk diterbitkan :09-10-2021

\begin{abstract}
Smartphone are tools that help life, even become daily needs for adolescents in Vocational High School (Sekolah Menengah Kejuruan or SMK) who live in urban areas. Unfortunately, not a few teenagers experience problems due to excessive smartphone use. These can include physical problems such as problems with the eyes, movement, and body position; as well as psychological problems such as unharmonious relationships with the people around them, or feeling dependent on devices. There are not many studies that describe the behavior and regulation of smartphone use in adolescents, especially vocational high school students in Indonesia. This study aims to obtain a description of the behavior of smartphone use among vocational high school students, as well as the settings up of regulations by the home and school environment. Participants are 1.921 high school students in 5 cities in 5 provinces in Indonesia (West Kalimantan, Yogyakarta Special Region (DIY), Bangka Belitung Islands, North Sulawesi, and Central Java). Data collection was carried out through a survey with a questionnaire specially designed by the researcher. Data collection was carried out before the COVID-19 Pandemic occurred. The results showed that in the period before the COVID-19 Pandemic, most students used smartphones for about 4-8 hours per day, for communication purposes. In addition, parents and schools make regulations regarding the use of smartphones. The results of this study can provide an overview, as well as a comparison for the description of the behavior of device use after the outbreak of the COVID19 outbreak.
\end{abstract}

Keywords: Behaviour, smartphone, vocational high school, regulation, Indonesia

\begin{abstract}
ABSTRAK
Telepon Genggam Cerdas (TGC) merupakan alat yang membantu kehidupan, bahkan menjadi kebutuhan sehari-hari bagi remaja di Sekolah Menengah Kejuruan (SMK) yang tinggal di daerah perkotaan. Sayangnya, tidak sedikit remaja yang mengalami masalah akibat penggunaan TGC yang berlebihan. Masalah itu dapat berupa masalah fisik seperti masalah pada mata, pergerakan, dan posisi tubuh; maupun masalah psikologis seperti hubungan yang kurang harmonis dengan orang-orang disekitarnya, atau merasakan ketergantungan terhadap gawai. Belum banyak studi yang menggambarkan perilaku dan pengaturan penggunaan TGC pada remaja khususnya siswa SMK. Penelitian ini bertujuan mendapatkan gambaran perilaku penggunaan gawai pada siswa SMK, serta pengaturan yang ditetapkan oleh lingkungan rumah dan sekolah. Partisipan adalah 1921 siswa SMK di 5 kota yang ada di 5 provinsi di Indonesia (Kalimantan Barat, Daerah Istimewa Yogyakarta (DIY), Kepulauan Bangka Belitung, Sulawesi Utara, dan Jawa Tengah). Pengumpulan data dilaksanakan melalui survei dengan kuesioner yang dirancang khusus oleh peneliti. Pengambilan data dilaksanakan sebelum terjadinya Pandemi COVID-19. Hasil penelitian menunjukkan bahwa pada masa sebelum Pandemi COVID-19, kebanyakan siswa menggunakan TGC selama sekitar 4-8 jam per-hari, untuk keperluan berkomunikasi. Selain itu, orang tua dan sekolah membuat aturan mengenai penggunaan TGC. Hasil penelitian ini dapat memberikan gambaran, sekaligus pembanding bagi gambaran perilaku penggunaan gawai sesudah merebaknya wabah COVID-19.
\end{abstract}

Kata Kunci: Perilaku, telepon genggam cerdas, sekolah menengah kejuruan, pengaturan, Indonesia 


\section{PENDAHULUAN}

\section{Latar Belakang}

Penting untuk mengetahui bagaimana manusia menggunakan teknologi, terutama dampak penggunaan teknologi terhadap individu dan masyarakat (Ellis et al., 2019). Perkembangan teknologi memungkinkan manusia memiliki hidup yang lebih baik. Gawai merupakan bagian dari perkembangan teknologi informasi terkini yang secara sadar atau tidak dapat menyebabkan ketergantungan (Dirgantara \& Kurniawan, 2015). Gawai atau gadget adalah peranti elektronik atau mekanik dengan fungsi praktis (Kementerian Pendidikan dan Kebudayaan Republik Indonesia, 2020). Salah satu bentuk gawai adalah TGC (Telepon Genggam Cerdas/Smartphone).

Smartphones atau di Indonesia biasa juga disebut telepon genggam cerdas atau TGC sudah menjadi kebutuhan dalam kehidupan masyarakat (Lee et al., 2014). Selama dekade terakhir, penggunaan TGC telah meluas di kalangan anak-anak dan remaja saat ini (Kim et al., 2016; Sohn et al., 2019). Adanya TGC dapat mendorong interaksi antar manusia dan juga mendorong seseorang mengerjakan sesuatu secara multitasking. Penggunaan TGC membantu kehidupan, contohnya mahasiswa menggunakan TGC sebagai alat bantu pembelajaran dan e-learning dan pembelajaran berbasis website.

Namun demikian, juga diketahui bahwa TGC memiliki dampak positif dan negatif (Lee et al., 2014), salah satunya pada performa akademik (Han \& Yi, 2019). Di sisi lain, terdapat kekhawatiran mengenai 'kecanduan smartphone' atau penggunaan TGC yang bermasalah (Sohn et al., 2019). Kecanduan ini terutama lebih rentan pada siswa Sekolah Menengah Atas (SMA). Studi yang dilakukan Lin et al. (2018) mengenai prevalensi adiksi internet pada sampel representatif siswa Sekolah Menengah Atas di Taiwan. Hasil penelitian menunjukkan bahwa prevalensi adiksi internet pada siswa SMA di Taiwan tinggi.

Penggunaan TGC yang berlebihan akan mengganggu kesehatan fisik (Kim et al., 2015; Jung et al., 2016) maupun psikologis (Ko et al., 2012; Sohn et al., 2019). TGC dapat berdampak buruk terhadap kesehatan, terutama pada mata. Hal ini dikarenakan pengguna TGC yang menatap layar terlalu lama. Paparan yang tinggi pada TGC menyebabkan prevalensi gejala okuler, seperti pandangan kabur, mata merah, gangguan penglihatan, pembengkakan, dan kekeringan mata (Kim et al., 2016). Partisipan dengan adiksi TGC cenderung kurang berjalan setiap hari. Adiksi internet dapat berdampak buruk bagi kesehatan fisik dengan mengurangi jumlah aktivitas fisik, seperti berjalan. Hal ini mengakibatkan meningkatnya massa berat badan dan menurunnya otot yang diasosiasikan dengan konsekuensi kesehatan yang buruk (Kim et al., 2015). Berdasarkan kesehatan fisik, penggunaan TGC dapat secara negatif mempengaruhi postur dan fungsi pernafasan (Jung et al., 2016).

Penggunaan TGC dapat menyebabkan permasalahan sosial, seperti depresi dan kerusakan fungsi sosial dan emosional (Kim et al., 2015). Lebih jauh lagi, adiksi internet dapat mengakibatkan penyalahgunaan substansi, depresi, dan gangguan kecemasan sosial (Ko et al., 2012). Siswa dengan adiksi TGC memiliki kemungkinan yang besar untuk mengalami kecemasan yang tinggi dibandingkan dengan siswa yang tidak kecanduan. Siswa yang memiliki kecemasan yang tinggi memiliki kesempatan yang lebih besar untuk memiliki masalah yang signifikan dalam hubungan keluarga mereka (Hawi \& Samaha, 2017). Penggunaan TGC yang bermasalah diasosiasikan dengan meningkatkan depresi, kecemasan, tingkat stres yang lebih tinggi dan kualitas tidur yang lebih buruk (Sohn et al., 2019). Penggunaan TGC yang bermasalah juga diasosiasikan dengan tingkat kesejahteraan yang lebih rendah dan perasaan negatif (negative affect) (Horwood \& Anglim, 2019). Penggunaan TGC yang bermasalah merupakan masalah kesehatan publik yang 
memerlukan studi lebih jauh untuk menentukan batas antara penggunaan teknologi yang berdampak baik dan berdampak buruk (Horwood \& Anglim, 2019; Sohn et al., 2019). Untuk itu diperlukannya suatu pedoman kebijakan untuk menguraikan strategi dampak buruk yang ditimbulkan dari penggunaan TGC (Sohn et al., 2019).

Penggunaan internet dapat menjadi bermasalah bagi beberapa orang dikarenakan adanya koneksi yang konstan, aplikasi-aplikasi yang menyebabkan adiksi, dan dikombinasikan dengan faktor psikologis personal seseorang (van Velthoven, Powell, \& Powell, 2018). Beberapa peneliti berusaha membuat intervensi untuk menangani penggunaan TGC yang berlebihan dan menimbulkan masalah, baik melalui pendekatan klinis, dan olahraga (Kim, 2013; Przepiorka et al., 2014).

Terdapat lima jenis intervensi yang efektif, yaitu: (a) involuntary restriction, (b) self-awareness dan self-control, (c) pembatasan sekolah (school restrictions), (d) dukungan teman sebaya (peer support), dan (e) bantuan profesional (Chun, 2018). Involuntarily restriction, salah satunya adalah pengendalian waktu penggunaan gawai (termasuk TGC) oleh orang tua. Self-awareness adalah kesadaran individu akan penggunaan TGC yang sudah berlebihan. Self-control adalah pengendalian diri individu akan penggunaan TGC. Pihak sekolah juga dapat membatasi penggunaan gawai, seperti waktu ujian, smartphone monitoring, dan peraturan sekolah yang melarang penggunaan TGC. Dukungan teman sebaya merupakan dukungan emosional, saran dan perilaku untuk membantu teman sebayanya berhenti menggunakan TGC. Bantuan profesional terdiri dari konseling kelompok ataupun individual, edukasi dan lainnya.

Pembatasan penggunaan TGC ditemukan memiliki dampak positif untuk mencegah seseorang menggunakan TGC secara bermasalah. Penelitian yang dilakukan Schmuck (2020) di Austria meneliti mengenai penggunaan aplikasi digital detox bagi penggunaan TGC yang bermasalah. Hasil penelitian menunjukkan bahwa bagi partisipan yang tidak menggunakan aplikasi digital detox secara positif diasosiasikan dengan penggunaan TGC yang bermasalah. Aplikasi digital detox dapat menjadi alat untuk mencegah dampak buruk dalam menggunakan situs jejaring sosial dan pada kesejahteraan pada anak muda dengan mengurangi resiko menggunakan TGC secara kompulsif. Berdasarkan hal ini, menjadi penting untuk menetapkan suatu aturan yang membatasi penggunaan gawai pada siswa di Indonesia. Namun demikian di Indonesia, belum banyak penelitian yang menggambarkan perilaku dan pengaturan penggunaan TGC pada remaja, khususnya siswa Sekolah Menengah Kejuruan Mengapa Sekolah Menengah Kejuruan? Karena Sekolah Menengah Kejuruan adalah pendidikan kejuruan yang pada umumnya melatih keterampilan-keterampilan praktis yang memerlukan latihan berulang sehingga dapat tercapai otomatisasi. Keterampilan ini dapat ditunjang dengan pembelajaran mandiri oleh siswa melalui materi-materi di internet, yang seringkali perlu diakses menggunakan TGC. Penelitian ini bertujuan mendapatkan gambaran perilaku penggunaan gawai pada siswa Sekolah Menengah Kejuruan, serta pengaturan yang ditetapkan lingkungan rumah dan sekolah.

\section{Rumusan Masalah}

Rumusan masalah dalam penelitian ini adalah: (a) berapa lamakah waktu yang digunakan siswa untuk menggunakan TGC setiap harinya?; (b) bagaimana gambaran keperluan penggunaan TGC siswa SMK?; (c) apakah terdapat aturan-aturan penggunaan TGC yang ditetapkan oleh lingkungan sekolah siswa tersebut?; dan (d) apakah terdapat aturan-aturan yang ditetapkan oleh orangtua siswa mengenai penggunaan TGC siswa? 


\section{METODE PENELITIAN}

Penelitian ini dilakukan pada 1.921 siswa Sekolah Menengah Kejuruan (SMK) yang berada pada 5 kota di 5 provinsi di Indonesia, yaitu: (a) Kalimantan Barat, (b) Daerah Istimewa Yogyakarta (DIY), (c) Kepulauan Bangka Belitung, (d) Sulawesi Utara, dan (e) Jawa Tengah. Partisipan ini terdiri dari 452 siswa laki-laki dan 1.469 siswa perempuan. Partisipan dalam penelitian ini berasal dari berbagai tingkat (kelas X-XII) dan berbagai jurusan (akuntansi, multimedia, pemasaran, dsb). Pengumpulan data dilaksanakan melalui survei dengan kuesioner yang dirancang khusus oleh peneliti. Pengambilan data dilaksanakan sejak tahun 2018 hingga tahun 2019, sebelum terjadinya Pandemi Coronavirus Disease 2019 (COVID-19).

Distribusi jumlah partisipan tiap daerah dapat dilihat pada tabel 1.

\section{Tabel 1}

Distribusi Jumlah Partisipan Tiap Daerah

\begin{tabular}{cccccc}
\hline No & Tahun & Daerah & Laki-laki & Perempuan & Total peserta \\
\hline 1 & 2018 & Pontianak & 46 & 37 & 83 \\
\hline 2 & 2018 & Yogyakarta & 23 & 215 & 238 \\
\hline 3 & 2019 & Manado & 148 & 157 & 305 \\
\hline 4 & 2019 & Salatiga & 17 & 782 & 799 \\
\hline 5 & 2019 & Tanjungpandan & 218 & 278 & 496 \\
\hline & & & $\mathbf{4 5 2}$ & $\mathbf{1 4 6 9}$ & $\mathbf{1 9 2 1}$
\end{tabular}

\section{HASIL DAN PEMBAHASAN}

Hasil penelitian menunjukkan sebagian besar siswa menggunakan waktu 4-8 jam. Hal ini dapat dilihat lebih jauh pada tabel 2.

\section{Tabel 2}

Lama Waktu Penggunaan TGC Setiap Harinya

\begin{tabular}{cc}
\hline Lama waktu penggunaan TGC setiap hari & Persentase (\%) \\
\hline Kurang dari 2 jam & 9 \\
\hline $2-4$ jam & 24 \\
\hline 4-8 jam & 36 \\
\hline 8-12 jam & 21 \\
\hline Lebih dari 12 jam & 9 \\
\hline Tidak menjawab & 1 \\
\hline Total & $\mathbf{1 0 0}$
\end{tabular}

Penggunaan TGC siswa selama 4-8 jam setiap harinya ditemukan sedikit lebih lama jika dibandingkan dengan penelitian terdahulu. Cha dan Seo (2018) menemukan bahwa pengguna TGC yang normal menghabiskan waktu kurang lebih sekitar 4-5 jam. Penelitian yang dilakukan Kibona dan Mgaya (2015) menemukan mayoritas partisipan menggunakan TGC selama 5-7 jam perhari. Sebagian besar siswa di empat provinsi menggunakan TGC selama 4-8 jam, namun lain halnya dengan daerah Pontianak. Siswa pada daerah Pontianak sebagian besar menggunakan waktu untuk bermain TGC selama 2-4 jam dalam sehari.

Terdapat beberapa keperluan penggunaan TGC siswa, diantaranya untuk berkomunikasi, sharing di media sosial, dan untuk mencari pengetahuan. Keperluan penggunaan TGC siswa dapat dilihat lebih jauh pada tabel 3. 


\section{Tabel 3}

Keperluan Utama Penggunaan TGC

\begin{tabular}{cc}
\hline Keperluan utama penggunaan TGC & Persentase (\%) \\
\hline Berkomunikasi & 49 \\
\hline Sharing di media sosial & 28 \\
\hline Bermain game online & 3 \\
\hline Mencari pengetahuan & 13 \\
\hline Keperluan lainnya & 5 \\
\hline Tidak menjawab & 2 \\
\hline Total & 100 \\
\hline
\end{tabular}

Berkomunikasi merupakan keperluan utama dalam penggunaan TGC siswa. Hal ini sejalan dengan penelitian terdahulu yang dilakukan Kibona dan Mgaya (2015) serta Cha dan Seo (2018) yang menyatakan bahwa sebagian besar partisipan dalam penelitiannya menggunakan internet untuk tujuan sosial, salah satunya adalah komunikasi. Pada penelitian terdahulu yang dilakukan Cha dan Seo (2018), setelah remaja menggunakan mobile messenger sebagai durasi terlama penggunaan TGC, tujuan penggunaan TGC siswa lainnya adalah menjelajahi internet. Penelitian Kibona dan Mgaya (2015) juga menemukan bahwa tujuan akademik sebagai salah satu tujuan penggunaan TGC kedua setelah untuk tujuan komunikasi.

Sebagian besar siswa di empat provinsi menggunakan TGC untuk berkomunikasi, namun di daerah Manado, terdapat proporsi yang cukup berimbang dalam keperluan penggunaan TGC siswa untuk berkomunikasi dan sharing di media sosial. Hal ini dapat dilihat lebih jauh pada tabel 4.

\section{Tabel 4}

\section{Keperluan Penggunaan TGC Berdasarkan Antar Daerah}

\begin{tabular}{lcccccc}
\hline \multirow{2}{*}{ Daerah } & \multicolumn{5}{c}{ Keperluan utama penggunaan TGC } \\
\cline { 2 - 7 } & Berkomunikasi & $\begin{array}{l}\text { Sharing di } \\
\text { media sosial }\end{array}$ & $\begin{array}{l}\text { Bermain } \\
\text { game online }\end{array}$ & $\begin{array}{l}\text { Mencari } \\
\text { pengetahuan }\end{array}$ & $\begin{array}{l}\text { Keperluan } \\
\text { lainnya }\end{array}$ & $\begin{array}{l}\text { Tidak } \\
\text { menjawab }\end{array}$ \\
\hline Pontianak & 48 & 15 & 3 & 3 & 12 & 2 \\
\hline Yogyakarta & 155 & 54 & 4 & 4 & 110 & 0 \\
\hline Belitung & 198 & 130 & 20 & 46 & 2 & 7 \\
\hline Manado & 115 & 116 & 19 & 96 & 39 & 3 \\
\hline Salatiga & 431 & 218 & 12 & 259 & 91 & 33 \\
\hline Total & 947 & 533 & 58 & 13 & 5 & 2 \\
\hline Persentase (\%) & 49 & 28 & 3 & & 21 \\
\hline
\end{tabular}

Sebagian besar orangtua siswa membuat aturan mengenai penggunaan TGC siswa, namun ada orang tua siswa yang tidak membuat peraturan mengenai penggunaan TGC siswa.

\section{Tabel 5}

Peraturan Orangtua dalam Menggunakan TGC

\begin{tabular}{cc}
\hline Peraturan orangtua dalam menggunakan TGC & Persentase (\%) \\
\hline Ada aturan & 56 \\
\hline Tidak ada aturan & 36 \\
\hline Tidak tahu & 7 \\
\hline Tidak menjawab & 1 \\
\hline Total & $\mathbf{1 0 0}$
\end{tabular}


Sebagian besar orangtua menetapkan peraturan dalam penggunaan TGC, kecuali di daerah Pontianak. Orangtua siswa di daerah Pontianak sebagian besar tidak membuat aturan bagi penggunaan TGC siswa.

Sebagian besar pihak sekolah juga menetapkan peraturan mengenai penggunaan TGC. Peraturan ini dapat dilihat lebih jauh pada tabel 6.

Tabel 6

Peraturan Sekolah Mengenai TGC

\begin{tabular}{cc}
\hline Peraturan sekolah dalam menggunakan TGC & Persentase \\
\hline Ada aturan & 80 \\
\hline Tidak ada aturan & 9 \\
\hline Tidak tahu & 10 \\
\hline Tidak menjawab & 1 \\
\hline Total & 100
\end{tabular}

Semua sekolah di lima provinsi secara menyeluruh sudah menerapkan peraturan mengenai penggunaan TGC.

Berdasarkan hasil penelitian, dapat disimpulkan bahwa sekolah dan orangtua sudah menetapkan aturan mengenai penggunaan TGC. Penentuan aturan ini diharapkan dapat membatasi penggunaan TGC siswa. Hal ini sejalan dengan penelitian Chun (2018) yang menyatakan bahwa peraturan pembatasan penggunaan TGC dari orangtua dan sekolah termasuk dalam kelompok intervensi yang efektif untuk mengatasi adiksi TGC. Hal ini juga sejalan dengan penelitian yang dilakukan Young (2010) yang menggunakan peraturan sebagai metode pencegahan dan intervensi penyalahgunaan internet.

\section{KESIMPULAN DAN SARAN}

Hasil penelitian menunjukkan bahwa pada masa sebelum Pandemi COVID-19, kebanyakan siswa menggunakan TGC selama sekitar 4-8 jam per-hari, sebagian besar siswa menggunakannya untuk keperluan berkomunikasi. Siswa juga menggunakan TGC untuk sharing di media sosial dan mencari pengetahuan. Selain itu, pada umumnya orang tua dan sekolah sudah membuat aturan mengenai penggunaan TGC siswa. Peraturan merupakan salah satu metode pencegahan dan intervensi terhadap penyalahgunaan internet. Hasil penelitian ini dapat menjadi memberikan gambaran, sekaligus pembanding bagi gambaran perilaku penggunaan gawai sesudah merebaknya wabah COVID-19.

\section{Ucapan Terima Kasih (Acknowledgement)}

Penelitian ini merupakan penelitian 3 tahun yang didukung oleh Direktorat Riset dan Pengabdian kepada Masyarakat, Kemenristek Dikti, Lembaga Penelitian dan Pengabdian kepada Masyarakat Universitas Tarumanagara. Peneliti mengucapkan terima kasih kepada para kepala sekolah beserta jajaran, yang telah memberikan izin melakukan penelitian lapangan di sekolah. Terima kasih pada guru serta siswa-siswi yang bersedia berpartisipasi dalam penelitian ini. Terima kasih atas bantuan Ibu Mei Ie, S.E., M.M dan Ibu Anny Valentina, S.Sn., M.Ds. Sn juga kepada para asisten riset dari fakultas Psikologi Alivia Fitriani Amanto, Claudia Fiscarina, Hartinah Dinata, dan Layla Adilla Ramadhani serta dari Fakultas Teknologi Informatika: Fenny Lusiana, Kirey Larasati, Linda Sari, dan Vivien H. Wangi yang telah membantu dalam proses pengambilan data lapangan. 


\section{REFERENSI}

Cha, S. S., \& Seo, B. K. (2018). Smartphone use and smartphone addiction in middle school students in Korea: Prevalence, social networking service, and game use. Health Psychology Open, 5(1). https://doi.org/10.1177/2055102918755046

Chun, J. S. (2018). Conceptualizing effective interventions for smartphone addiction among Korean female adolescents. Children and Youth Services Review, 84, 35-39. https://doi.org/10.1016/j.childyouth.2017.11.013

Dirgantara, A., \& Kurniawan, A. (2015). Sosialisasi cara penanggulangan perubahan perilaku sosial anak akibat bermain gawai secara berlebihan. Jurnal Telematika, 10(1), 5. https://journal.ithb.ac.id/telematika/article/view/127/134

Ellis, D. A., Davidson, B. I., Shaw, H., \& Geyer, K. (2019). Do smartphone usage scales predict behavior? International Journal of Human Computer Studies, 130, 86-92. https://doi.org/10.1016/j.ijhcs.2019.05.004

Han, S., \& Yi, Y. J. (2019). How does the smartphone usage of college students affect academic performance? Journal of Computer Assisted Learning, 35(1), 13-22. https://doi.org/10.1111/jcal.12306

Hawi, N. S., \& Samaha, M. (2017). Relationships among smartphone addiction, anxiety, and family relations. Behaviour and Information Technology, 36(10), 1046-1052. https://doi.org/10.1080/0144929X.2017.1336254

Horwood, S., \& Anglim, J. (2019). Problematic smartphone usage and subjective and psychological well-being. Computers in Human Behavior, 97, 44-50. https://doi.org/10.1016/j.chb.2019.02.028

Jung, S. I., Lee, N. K., Kang, K. W., Kim, K., \& Lee, D. Y. (2016). The effect of smartphone usage time on posture and respiratory function. Journal of Physical Therapy Science, 28(1), 186189. https://doi.org/10.1589/jpts.28.186

Kementerian Pendidikan dan Kebudayaan Republik Indonesia. (2020). KBBI daring. https://kbbi.kemdikbud.go.id/Beranda

Kibona, L., \& Mgaya, G. (2015). Smartphones' effects on academic performance of higher learning students. Journal of Multidisciplinary Engineering Science and Technology (JMEST), 2(4), 777-784. https://www.jmest.org/wpcontent/uploads/JMESTN42350643.pdf

Kim, H. (2013). Exercise rehabilitation for smartphone addiction. Journal of Exercise Rehabilitation, 9(6), 500-505. https://doi.org/10.12965/jer.130080

Kim, J., Hwang, Y., Kang, S., Kim, M., Kim, T. S., Kim, J., Seo, J., Ahn, H., Yoon, S., Yun, J. P., Lee, Y. L., Ham, H., Yu, H. G., \& Park, S. K. (2016). Association between exposure to smartphones and ocular health in adolescents. Ophthalmic Epidemiology, 23(4), 269-276. https://doi.org/10.3109/09286586.2015.1136652

Kim, S. E., Kim, J. W., \& Jee, Y. S. (2015). Relationship between smartphone addiction and physical activity in Chinese international students in Korea. Journal of Behavioral Addictions, 4(3), 200-205. https://doi.org/10.1556/2006.4.2015.028

Ko, C. H., Yen, J. Y., Yen, C. F., Chen, C. S., \& Chen, C. C. (2012, January). The association between Internet addiction and psychiatric disorder: A review of the literature. European Psychiatry, 27, 1-8. https://doi.org/10.1016/j.eurpsy.2010.04.011

Lee, Y.-K., Chang, C.-T., Lin, Y., \& Cheng, Z.-H. (2014). The dark side of smartphone usage: Psychological traits, compulsive behavior and technostress. Computers in Human Behavior, 31, 373-383. https://doi.org/10.1016/j.chb.2013.10.047 
Lin, M. P., Wu, J. Y. W., You, J., Hu, W. H., \& Yen, C. F. (2018). Prevalence of internet addiction and its risk and protective factors in a representative sample of senior high school students in Taiwan. Journal of Adolescence, 62, 38-46. https://doi.org/10.1016/j.adolescence.2017.11.004

Przepiorka, A. M., Blachnio, A., Miziak, B., \& Czuczwar, S. J. (2014, March 2). Clinical approaches to treatment of Internet addiction. Pharmacological Reports, 66, 187-191. https://doi.org/10.1016/j.pharep.2013.10.001

Schmuck, D. (2020). Does digital detox work? Exploring the role of digital detox applications for problematic smartphone use and well-being of young adults using multigroup analysis. Cyberpsychology, Behavior, and Social Networking. 23(8), 526-532. https://doi.org/10.1089/cyber.2019.0578

Sohn, S., Rees, P., Wildridge, B., Kalk, N. J., \& Carter, B. (2019, November 29). Prevalence of problematic smartphone usage and associated mental health outcomes amongst children and young people: a systematic review, meta-analysis and GRADE of the evidence. BMC Psychiatry, Vol. 19, p. 356. https://doi.org/10.1186/s12888-019-2350-x

van Velthoven, M. H., Powell, J., \& Powell, G. (2018). Problematic smartphone use: Digital approaches to an emerging public health problem. Digital Health, 4, 205520761875916. https://doi.org/10.1177/2055207618759167

Young, K. (2010). Policies and procedures to manage employee Internet abuse. Computers in Human Behavior, 26(6), 1467-1471. https://doi.org/10.1016/j.chb.2010.04.025 